\title{
EXÍLIO E SENTIMENTO NA CIDADE EM "LAS VENTANAS SE HAN ESTREMECIDO", DE CÉSAR VALLEJO
}

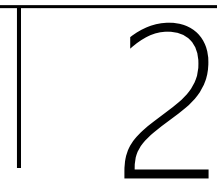

\section{EXILE AND FEELING IN THE CITY IN "LAS VENTANAS SE HAN ESTREMECIDO' BY CÉSAR VALLEJO}

\begin{abstract}
LANNOY, Lucie Josephe de
Doutora em Literatura. Professora Adjunta de Língua Espanhola junto ao Departamento de Línguas Estrangeiras e Tradução, do Instituto de Letras da Universidade de Brasília, no Distrito Federal.

E-mail: http://lattes.cnpq.br/791418190487482
\end{abstract}

\section{BARBOSA, Sidney}

Doutor e Língua e Literatura Francesa. Livre-Docente, Professor Associado de Literatura Francesa junto ao Departamento de Teoria Literária e Literaturas da Universidade de Brasília e docente do Programa de PósGraduação em Literatura da mesma Universidade. Líder do Grupo Interinstitucional de Pesquisa TOPUS, dedicado ao estudo do espaço na Literatura e em outras artes e do LiterArtes, consagrado ao estudo das relações entre Literatura e outras artes.

E-mail: sidneyb@unb.br

ORCID ID: https://orcid.org/0000-0001-8976-563X

\section{RESUMO}

O poema "Las ventanas se han estremecido" ("As janelas estremeceram") faz parte da obra do poeta peruano César Vallejo (1892-1938) Poemas Póstumos I, também chamados Poemas Humanos ou Los poemas de París. A análise, realizada segundo $A$ poética do espaço, de Gaston Bachelard (1884-1962), e as próprias reflexões do poeta, registradas em artigos e crônicas, contemplam uma relação ambígua do autor com a cidade do seu exílio, Paris. É a partir desse espaço, no entanto, que o artista toma consciência de aspectos culturais e sociais da América Latina e os apresenta traduzidos sensorialmente em sua poesia.

Palavras-chave: Poesia peruana; espaço na poesia; César Vallejo; escrita do exílio; poesia moderna.

\section{ABSTRACT}

The poem "Las ventanas se han trembled" ("The windows were shaken") is part of the work of the Peruvian poet César Vallejo (1892-1938) Poemas Póstumos I, also called Human poems or The Poems of Paris. The analysis was carried out according to Gaston Bachelard's (1884-1962), The Poetics of Space and the poet's own reflections, which come from his articles and chronicles, contemplating an ambiguous relationship between the author and the city of his exile, Paris. It is from this space, however, that the artist becomes aware of cultural and social aspects of Latin America and presents them translated in a sensorial way in his poetry. 
Keywords: Peruvian poetry; space in poetry; César Vallejo; writing from exile; modern poetry.

\section{INTRODUÇÃO}

César Abraham Vallejo Mendoza (1938-1982), filho de Francisco de Paula Vallejo Benítez e neto do sacerdote espanhol da Galícia, José Rufo Vallejo e da índia Chimú, Justa Benítez e de María de los Santos Mendoza Gurrionero (filha também do sacerdote espanhol Joaquín de Mendoza e da índia Natividad Gurrionero), nasceu em Santiago de Chuco, na província peruana de La Libertad e foi o caçula de uma família de onze filhos. Segundo uma tradição espanhola que se aplicava parcialmente no contexto criolo, o filho mais jovem de uma família burguesa deveria tornar-se padre. Sendo o seu pai escrivão, aprendeu, desde cedo que escrever bem conferia autoridade e realização social. Desse modo, ainda que tendo uma infância em condições humildes, a cultura e a religiosidade do lugar impregnaram a sua formação. Vallejo estudou em Trujillo, capital da Província e, na época da conclusão dos estudos, escreveu uma tese sobre o Romantismo. Nesse período (19191920) ${ }^{1}$, o Peru vivia um momento de mudanças políticas. Em uma visita que o poeta fez a sua família houve um levante popular e ele foi acusado pelas autoridades de ser o mentor da revolta, sendo preso, injustamente, por cento e vinte dias. Nesse período, ele escreveu a obra Trilce (1922), uma obra que pode ser considerada de vanguarda, tanto pela forma como pelo conteúdo. Mas, como consequência desses problemas políticos exila-se na França.

É nesse contexto que Vallejo parte do Peru para, sem o saber ou desejar, nunca mais voltar. Será difícil para ele abrir um caminho à força de aventurar-se no desconhecido. A sua vida na Cidade-Luz o expõe ainda mais à pobreza, quase à miséria. Porém, os desafios farão dele também um ser comprometido com o destino do seu país e solidário com as causas do povo espanhol na Guerra Civil, incorporando-as à sua própria escrita. E se a sua obra mais inovadora fora Trilce, produzida no sofrimento e na injustiça de sua terra, será em Paris que ele realizará até o fim aquele destino prenunciado por seu amigo Orrego ${ }^{2}$, o de amadurecer 0 estilo e a expressão poética e criar valores e propostas estéticas pessoais.

${ }^{1}$ Nesse período, destaca-se o governo de Auqusto B. Lequía e as disputas intestinas do Estado peruano passam por um golpe e pela promulgação da Carta Magna de 1929.

2 Orrego, Antenor (apud: Candela, G.P. El proceso Vallejo, Trujillo: Universidad Nacional de Trujillo, 1992: 13). 


\section{ANÁLISE DO POEMA}

César Vallejo chega a Paris, em julho de 1923, sem saber falar francês e desempregado. Durante dois anos tem problemas para se manter e, provavelmente, por padecer diversas necessidades, adoece. Em 24 de março de 1924, recebe a notícia do falecimento de seu pai. Essa dolorosa notícia, somada à sua má alimentação e às angústias econômicas, provocou-Ihe uma crise nervosa (VIGIL, 2005). Em outubro daquele ano, adoece gravemente e é operado de hemorragia intestinal no Hospital de la Charité.

Essa experiência pessoal dolorosa e melancólica está registrada no poema "Las ventanas se han estremecido", o qual apresenta cento e dez versos livres com variado número de sílabas métricas (versos anisossílabos). O texto alude, de modo geral, ao hospital e se relaciona à vivência do próprio Vallejo, que compartilhou um dos quartos com outros doentes. O tema da autobiografia em Poemas Humanos é raro e serve apenas como ponto de partida para expressar, no caso deste poema, "quão doloroso é ter que morrer de costas para os homens" (REYNOLDS, 1970):

Las ventanas se han estremecido, elaborando una metafísica del universo. Vidrios han caído. Un enfermo

lanza su queja: la mitad por su boca lenguada y sobrante, y toda entera, por el ano de su espalda.

Es el huracán. Un castaño del jardín de las Tullerías habrase abatido, al soplo del viento, que mide ochenta metros por segundo. Capiteles de los barrios antiguos, habrán caído, hendiendo, matando.

¿De qué punto interrogo, oyendo a ambas riberas de los océanos, de qué punto viene este huracán, tan digno de crédito, tan honrado de deuda, derecho a las ventanas del hospital?iAy las direcciones inmutables, que oscilan entre el huracán y esta pena directa de toser o defecar! iAy! las direcciones inmutables, que así

prenden muerte en las entrañas del hospital y despiertan células clandestinas, a deshora, en los cadáveres.

(...) (VALLEJO, 1996, p. 312).

Este poema inicia-se com um tema semelhante ao do poema I, da obra Trilce: 
Testar las islas que van quedando.

Un poco más de consideración

(...)

Y el mantillo líquido, seis de la tarde

DE LOS MÁS SOBERBIOS BEMOLES.

Y la península párase

Por la espalda, abozalada, impertérrita

En la línea mortal del equilibrio. (VALLEJO, 1996, p. 170).

Afinal, estar em um quarto de hospital é, de certa forma, como estar no isolamento de uma prisão. Segundo a Poética do espaço (BACHELARD, 1974), pela explosão de uma imagem (como a das janelas que estremeceram ou a dos vidros que caíram devido a um estrondo), o passado longínquo (o da prisão de Vallejo) ressoa em ecos e não se pode mais discernir até onde se trata da repercussão daquela experiência ou se inicia uma nova. As linguagens dos dois poemas seguem projetos diferentes. Contudo, ambos fazem alusão ao barulho de uma eliminação de gases intestinais. Em Trilce, o tema abrange todo o poema. Já, nesse longo poema, sugere-se isso apenas nas quatro primeiras estrofes.

Ao relacionar este fato com Paris, observa-se que há barulho também na cidade, devido a um "furacão". Paris figura como metáfora pela qual os "capitéis" que caem equivaleriam ao excremento defecado. Contudo, o que fala mais alto no poema não é nem a flatulência e nem o furacão, mas um lamento. Há um reclamo: "iAy! las direcciones inmutables!", em um tom que expressa desejo de mudança. No poema entram em choque frontal os dois espaços que colidem de forma a tornar possível essa mudança, realizando o desejo do poeta: assim como a árvore ou os capitéis dos bairros antigos, desabaram os vidros das janelas que estremeceram. O mundo interior (da clínica) e exterior (da cidade) unifica-se, tornando-se o próprio universo a habitação do poeta, pois "todo espaço verdadeiramente habitado traz a essência da noção de casa" (BACHELARD, 1974: 200). O espaço assim transformado torna-se a própria expressão da emoção do poeta.

Vallejo foi operado dos intestinos. E o eu lírico, em outra parte do mesmo poema, questiona-se:

¿Cuánto tiempo ha durado la anestesia, que llaman los hombres?iCiencia de Dios, Teodicea! isi se me echa a vivir en tales condiciones, anestesiado totalmente, volteada mi sensibilidad para adentro! iAh doctores de las sales, hombres de las esencias, prójimos de las bases!ipido se me deje con mi tumor de conciencia, con mi irritada lepra sensitiva, ocurra lo que ocurra, aunque me muera! Dejadme dolerme, si lo queréis, mas dejadme despierto de sueño, con todo el 
universo metido, aunque fuese a las malas, en mi temperatura polvorosa. (VALLEJO, 1996, p. 312).

Ele expressa toda a angústia que a possibilidade de ficar anestesiado Ihe causa, a ponto de pensar na morte. Ele compara a dor física com a dor psicológica ou moral. A anestesia serve para mitigar a dor física, mas se tiver que servir também para diminuir a dor moral, o poeta revolta-se: "ipido que me deje com mi tumor de conciencia!". Se a vida tem sentido, a dor também o terá: o poeta prefere que o deixem sofrer, "Dejadme dolerme" (...), mas/dejadme despierto de sueño, con todo el universo me-/tido, aunque fuese a las malas, em mi tempereatura polvo-/rosa." A escrita desse poema em prosa repercute até nos mínimos detalhes como a forma de separar as palavras. Quando o poeta escreve "polvorosa", será que o fez consciente do jogo de palavras ao separar "polvo" (pó) de "rosa" (rosa)? Todo esse imaginário colabora para habitar com um novo olhar o lugar onde está vivendo, por meio de uma dialética elaborada entre a realidade e a arte. Parece sugerir que o sentido da dor esteja no ficar acordado, com um sonho vivo, do qual comungam o poeta e o universo. Com a quebra dos vocábulos/versos, mormente em "polvo/rosa" Vallejo quebra não apenas o dualismo sintático/morfológico, mas ao mesmo tempo a cadeia sinestésica que transforma comparações, num primeiro nível, em plasticidade metafórica, ou seja, denuncia, nas palavras e pelas palavras, o contrapelo da língua: "polvo/rosa" converte-se em "polvo" "rosa" e ao mesmo pode-se ler "polvorosa" passando assim da dimensão orgânica animal - como o "eu" lírico do poema, despido do sentimento do mundo pela anestesia sinestésica dos sentidos humanos, em confronto com o que revelam as "janelas/ventanas" do sentido físico desse mundo que teima em ser orgânico/inorgânico. Desse modo, o poeta quebra essa dualidade reflexiva e o homem, triste animal doente e combalido pela ciência do mundo, volta a ser triste e combalido e de novo, como propunham as teses científicas daquele momento do poeta, a aporia duplica-se nesse corpo mundo e mundo corpo, porque não há mais comparações sinestésicas para igualar ou para passar de um universo a outro ou de uma imagem para outra. E é desse modo que a imagem do eu lírico amplificado no espaço fala no âmago do ser para o ser no seu âmago. Bachelard (1974. p.183-184), diz-nos que não é na causalidade mas na repercussão (retentissement) "que acreditamos encontrar as verdadeiras medidas do ser de uma imagem poética. Nessa percussão, a imagem poética terá uma sonoridade do ser. Será necessário, pois, para determinar o ser de uma imagem, senti-la em sua repercussão".

Bachelard (1974, p. 200) retoma essa dualidade de "habitações" e seus "cantos" como uma condição do homem no ser e do ser no homem, ou ainda do homem na cidade e da cidade no homem, ou ainda seus 
"aposentos":

É preciso dizer então como habitamos nosso espaço vital de acordo com todas as dialéticas da vida, como nos enraizamos, dia a dia, num "canto do mundo". Pois a casa é nosso canto do mundo. Ela é, como se diz freqüentemente, nosso primeiro universo. É um verdadeiro cosmos. Um cosmos em toda a acepção do termo. Até a mais modesta habitação, vista intimamente, é bela. Os escritores de "aposentos simples" evocam com freqüência esse elemento da poética do espaço. Mas essa evocação é sucinta demais. Tendo pouco a descrever no aposento modesto, tais escritores quase não se detêm nele. Caracterizam o aposento simples em sua atualidade, sem viver na verdade a sua primitividade, uma primitividade que pertence a todos, ricos e pobres, se aceitarem sonhar.

A imagem poética da cidade, do homem, do local, do aposento, em suma a "poética do espaço" é um reflexo dialógico do "sentimento do mundo", de Carlos Drummond de Andrade, e também daquela poesia enfincada nessas fratrias palavras de Ortega y Gasset:

Quando não há alegria, a alma se retira para um lugar de nosso corpo e faz dele seu covil. De quando em quando dá um doloroso uivo ou mostra os dentes para as coisas que passam. E parece que todas as coisas abrem caminho, sujeitas ao fardo de seu destino, e nenhuma tem vigor o bastante para dançar com ele sobre os ombros. A vida nos oferece um panorama de escravidão universal. Nem a trêmula árvore, nem a serra que incorpora vacilante seu peso, nem o velho monumento que perpetua em vão sua exigência de ser admirado, nem o homem, que, ande por onde ande, leva sempre o semblante de estar subindo uma encosta - nada, ninguém manifesta maior vitalidade que a estritamente necessária para alimentar sua dor e sustentar em pé sua desesperação.

$\mathrm{E}$, ademais, quando não há alegria, cremos fazer um atroz descobrimento. Muito especialmente se a falta de alegria provém de uma dor física percebemos com estranha evidência a linha negra que limita cada ser e o encerra dentro de si, sem janelas para fora, como dizia Leibniz, porém sem o infinito que esse homem feliz colocava dentro de cada um. Este é o descobrimento que fazemos por meio da dor como se fosse por meio de um microscópio: a solidão de cada coisa. (ORTEGA Y GASSET, 2013, p. 31) 
Vallejo não pode deixar a sua enfermaria e nem fazer menos do que sonhar e fazer sonhar. Cabe ao leitor, decidir de que universo se trata, segundo a atualidade da leitura. Após a experiência estética que nos transmite o poeta ao expressar a sua emoção que se expande para além dos muros do hospital, não apenas transforma-se o espaço que habita mas, o universo e a dor o levam a concluir o poema começando um diálogo com um Deus próximo, em forma de litania, repetindo três vezes a mesma estrofe que apenas mudará o tempo do verbo do presente para o passado no último verso: "que se pôde deixar na vida!:

iNo es grato morir, señor, si en la vida nada se deja y si en la muerte nada es posible, sino sobre lo que se deja en la vida! (VALLEJO, 1996, p. 312).

Como já expressado por Reynolds (1970: 160), "a ideia de morrer sem realizar-se na vida, priva à própria morte de transcendência". Pois, de fato, se a vida tem sentido, terá sentido não só a dor, mas, também, a morte. Entretanto, ao relacionar a noção de transcendência com o Absoluto, a Verdade, Girardot (1996: 519) observa que, para Vallejo, "a Verdade não é Deus mas, um estado prévio da vida do homem que se perdeu". Segundo Vigil (2005: 22), ao poeta não Ihe interessam dogmas, preceitos de uma catequese teológica e nem uma crença cerebral abstrata. Ele está mais interessado na divinização do ser humano e deste mundo do que com a vida no além.

Entretanto, não se trata de pensar em Paris, onde viveu Vallejo nesse tempo de exílio, como uma cidade pouco acolhedora ou um lugar de provação, apenas. A relação de Vallejo com a Cidade-Luz é ambígua. Por um lado, o poeta sente-se renascer, como ele mesmo diz: "Percebo-me em um país estranho, no qual tudo ganha aspecto de nascimento, luz de epifania imarcescível $^{3 \prime \prime}$ (VALLEJO, 1996, p. 298). E, por outro lado, Franco (1996, p. 592) lembra que, outras vezes, Vallejo "observa uma cidade que se destrói, uma cidade não de luzes mas de janelas quebradas, de hospitais e de morte", como, de fato, ele o expressa no poema que analisamos, "As janelas estremeceram". Afinal, Paris proporciona-lhe, por um lado, o contato com poetas, escritores, pintores, músicos latino-americanos e estrangeiros, o que enriqueceu o seu imaginário. Mas, por outro lado, Vallejo esteve, também, marginalizado pela sua pobreza.

Os anos 1930 foram, para o mundo do período entre guerras, extremamente desafiadores. Na condição de estrangeiro, Vallejo enfrentou árduas dificuldades. Porém, ele soube encontrar sentido e, por meio da arte

\footnotetext{
${ }^{3}$ Me advierto en un país extraño, en el que todo cobra relieve de nacimiento, luz de de epifanía inmarcesible. (VALLEJO, 1996, p. 298).
} 
e do seu engajamento, brindou ao mundo sinais de esperança. Paris será o palco no qual Vallejo ensaiará a sua poética do espaço, no sentido de servirse deste, como meio para expressar o seu lirismo. Os lugares que aparecem nas suas crônicas e poesias configuram símbolos por meio dos quais transforma a realidade. Ele cria uma linguagem capaz de inverter, por exemplo, a situação de estranhamento em um lugar familiar; na rua, espaço do anonimato, cria visibilidade; na distância, encontra a proximidade. E, aos poucos, durante as viagens à União Soviética ou durante a Guerra Civil Espanhola, aperfeiçoará ainda mais essa arte: onde cidades bombardeadas ou campos de batalha, símbolos de injustiça e destruição, permeiam-se de uma ótica de solidariedade e abertura para um sentido novo.

Vallejo sofre e, ao mesmo tempo, observa a vida em Paris. E assim como ama a cidade, ele, com a óptica de quem já possui uma vivência em outros lugares, consegue descrever aspectos retrógrados da cultura, mas também se nutre da alegria de acompanhar a "loucura insubstituível da arte" (Caisso, apud Vallejo, 1994: 12). Ele parece interrogar-se sobre as possibilidades do destino humano, como dirá em um poema em prosa: "Hay, madre, un sítio en el mundo, que se llama París. Un sítio muy grande y lejano y outra vez grande" (Vallejo, 1996: 309, "Poema Póstumo I", El buen sentido).

Segundo Bachelard (1974: 200), se quisermos determinar a realidade profunda de cada um dos matizes de nossa atração por um lugar escolhido, quantos problemas conexos encontraremos. "Para um fenomenólogo, o matiz deve ser tomado como um fenômeno psicológico de primeira ordem. O matiz não é uma coloração superficial suplementar. É preciso dizer, então, como habitamos"

"Em Paris tudo é possível", torna a dizer algumas vezes o poeta. Segundo Caisso (op. cit.,p. 311), essa frase aparece em muitos textos - tais como: "O assassino de Barrès" (op. cit., p. 313, v. II), "A visita dos reis de Espanha a Paris" (op. cit., p. 247), "O crepúsculo das águias" (op. cit., p. 399), "Crônica de Paris" (op. cit., p. 187, v. I) - depois de criticar a frivolidade, de ter polemizado postulados de vanguarda, de ter hostilizado os ritos dos funerais ou indagado sobre a cultura. Ele observa a vida com uma mistura de admiração e desconfiança. Preocupa-se com a dimensão humana do homem comum. E adota, em relação a Paris, a postura de alguém que deve ouvir e aprender obedientemente de modo a poder reencontrar o prazer do filho junto à mãe, essa mãe cuja dimensão é totalizante, unânime com o desejo do filho de superar distâncias, unificar mundos, consolar-se. Pois, como diz Bachelard (1974: 201) "o verdadeiro bem-estar tem um passado". Em Vallejo está, certamente, relacionado à figura materna.

Há muitos poemas que fazem referência a Paris. Em Poemas Humanos, contudo, estas alusões à cidade servem como meio para situar ou explicar as atitudes emotivas do poeta. Como diz Reynolds (1970: 52): Em Poemas 
Humanos, a Vallejo não Ihe preocupam o relato do lugar, no sentido de história ou descrição: interessa-lhe o homem em si e seus semelhantes, sem tradição nem futuro. Somente ele, como é e com aquilo que existe na sua situação agônica e transitória pelo mundo".

\title{
CONCLUSÃO
}

Esse foi o caminho que percorreu a sua escrita e que lhe permitiu encarar a miséria da América, fazendo com que assumisse a convicção de que a escrita nunca pode ser neutra. Desse modo, ele se coloca cada vez mais a serviço da sociedade transmitindo uma visão crítica e vivendo também um espaço de solidariedade. Isso fará com que ele diga que:

\begin{abstract}
A minha maior aspiração é a de eliminar toda palavra de existência acessória... uma vez que não se pode renunciar às palavras! Acredito sinceramente que a poesia possui um sentido histórico do idioma e que às apalpadelas procura, com justeza, a sua expressão (VALLEJO, 1992, p. 54) 4 .
\end{abstract}

Expressão que não ocorre sem ecos e leituras de leituras. E assim como as palavras falam de palavras, os gestos repetem os gestos, como "se honra el animal que me honra". E nesse jogo de duplicidades em que variados seres caminham um ao lado do outro, um disfarçado de outro, como nessa citação desse poema "España, aparta de mí este cáliz" (1937), em que a imagem da cidade do homem, "aposentos", e reflexos e falas e palavras percorrem esse túnel infinito e inusitado feito de vocábulos e cifras. O ser no tempo da vida é distinto do tempo no ser, mas ambos são, paradoxalmente, ao mesmo tempo, uma espécie de cainismo (de Caim, o ritualístico, fratricida, porém protegido de Deus) e abelismo (de Abel, o que apresentava a oferenda perfeita, vítima santa, o cordeiro a ser ele próprio oferecido em sacrifício). Assim, dever-se-ia propor, ao invés do ser no tempo, o tempo do ser. E o verbo então progrediria até realizar-se inteiramente em morrerei, morri, morro.

\section{REFERÊNCIAS BIBLIOGRÁFICAS}

BACHELARD, Gaston. A poética do espaço. Tradução Antônio Antonio de

\footnotetext{
${ }^{4}$ Mi mayor aspiración es la eliminación de toda palabra de existencia accesoria....iya que no se puede renunciar a las palabras! Creo sinceramente que la poesía posuee un sentido histórico del idioma y que busca a tientas, con justicia, su expresión (VALLEJO, 1992, p. 54).
} 
Pádua Danes. 2. ed. São Paulo: Martins Fontes, 2008.

CANDELA, Germán Patrón. El Proceso Vallejo. Trujillo: Ed. Universidad Nacional de Trujillo, 1992.

FRANCO, Jean. La desautorización de la voz poética en dos poemas de Vallejo. Actas del coloquio internacional Freie Universität Berlin, 1981: 54-63. In: VALLEJO, Cesar. Obra poética. Ed. crítica, Américo Ferrari (Org.). Colección Archivos de la UNESCO, ALLCA XX/ São Paulo, EDUSP, 1996.

GIRARDOT, Gutierrez Rafael. La muerte de Dios en aproximaciones a César Vallejo, 1971:335-350. In: VALLEJO, Cesar. Obra poética. Ed. crítica, Américo Ferrari (Org.). Colección Archivos de la UNESCO, ALLCA XX/ São Paulo: EdUSP, 1996.

ORTEGA Y GASSET, José. A beleza foi feita para ser roubada. Tradução Ricardo Araújo. Brasília: Ed. UnB, 2013.

VALLEJO, César. Poesia completa. Tradução Thiago de Mello. Rio de Janeiro: Philobiblion/Rioarte, 1984.

VALLEJO, César. Antología Poética. Barcelona: Ediciones 29, 2000.

VALLEJO, César. El arte y la revolución: libro de pensamientos. Prólogo de Ricardo González VIGIL. Lima: Editora Perú, 2005. Disponível em: <http://www.scribd.com/doc/15789118/Cesar-Vallejo-El-Arte-y-LaRevolucion>. Acesso em: 26 nov. 2012.

VALLEJO, César. Escritos en prosa. Selección y estudio preliminar Claudia Caisso. Buenos Aires: Losada, 1994.

VALLEJO, César. Obra poética. Ed. crítica, Américo Ferrari (Org.). Colección Archivos de la UNESCO, ALLCA XX/ São Paulo: EDUSP, 1996.

\section{ANEXO}

\section{LAS VENTANAS SE HAN ESTREMECIDO}

Las ventanas se han estremecido, elaborando una metafísica del universo. Vidrios han caído. Un enfermo lanza su queja: la mitad por su boca lenguada y sobrante, y toda entera, por el ano de su espalda.

Es el huracán. Un castaño del jardín de las Tullerías habrase abatido, al soplo del viento, que mide ochenta metros por segundo. Capiteles de los barrios antiguos, habrán caído, hendiendo, matando. 
¿De qué punto interrogo, oyendo a ambas riberas de los océanos, de qué punto viene este huracán, tan digno de crédito, tan honrado de deuda, derecho a las ventanas del hospital?iAy las direcciones inmutables, que oscilan entre el huracán y esta pena directa de toser o defecar!iAy! Las direcciones inmutables, que así prenden muerte en las entrañas del hospital y despiertan células clandestinas, a deshora, en los cadáveres.

¿Qué pensaría de sí el enfermo de enfrente, ése que está durmiendo, si hubiera percibido el huracán? El pobre duerme, boca arriba, a la cabeza de su morfina, a los pies de toda su cordura. Un adarme más o menos en la dosis y le llevarán a enterrar, el vientre roto, la boca arriba, sordo al huracán, sordo a su vientre roto, ante el cual suelen los médicos dialogar y cavilar largamente, para, al fin, pronunciar sus llanas palabras de hombres.

La familia rodea al enfermo agrupándose ante sus sienes regresivas, indefensas, sudorosas. Ya no existe hogar sino entorno al velador del pariente enfermo, donde montan guardia impaciente, sus zapatos vacantes, sus cruces de repuesto, sus píldoras de opio. La familia rodea la mesita por espacio de un alto diviDendo. Una mujer acomoda en el borde de la mesa, la Taza, que casi se ha caído.

Ignoro lo que será del enfermo esta mujer, que le besa y no puede sanarle con el beso, le mira y no puede sanarle con los ojos, le habla y no puede sanarle con el verbo. ¿Es su madre?¿YY cómo, pues, no puede sanarle? Porque esta mujer le ha besado, le ha mirado, le ha hablado y hasta le ha cubierto mejor el cuello al enfermo y icosa verdaderamente asombrosa! no le ha sanado.

El paciente contempla su calzado vacante. Traen queso. Llevan tierra. La muerte se acuesta al pie del lecho, a dormir en sus tranquilas aguas y se duerme. entonces, los libres pies del hombre enfermo, sin menudencias ni pormenores innecesarios, se estiran en acento circunflejo, y se alejan, en una extensión de dos cuerpos de novios, del corazón.

El cirujano ausculta a los enfermos horas enteras. Hasta 
donde sus manos cesan de trabajar y empiezan a jugar, las lleva a tientas, rozando la piel de los pacientes, en tanto sus párpados científicos vibran, tocados por la indocta, por la humana flaqueza del amor. $Y$ he visto a esos enfermos morir precisamente del amor desdoblado del cirujano, de los largos diagnósticos, de las dosis exactas, del riguroso análisis de orinas y excrementos. Se rodeaba de improviso un lecho con un biombo. Médicos y enfermeros cruzaban delante del ausente, pizarra triste y próxima, que un niño llenara de números, en un gran monismo de pálidos miles. Cruzaban así, mirando a los otros, como si más irreparable fuese morir de apendicitis o neumonía, y no morir al sesgo del paso de los hombres.

Sirviendo a la causa de la religión, vuela con éxito esta mosca, a lo largo de la sala. A la hora de la visita de los cirujanos, sus zumbidos nos perdonan el pecho, ciertamente, pero desarrollándose luego, se adueñan del aire, para saludar con genio de mudanza, a los que van a morir. Unos enfermos oyen a esa mosca hasta durante el dolor y de ellos depende, por eso, el linaje del disparo, en las noches tremebundas.

¿Cuánto tiempo ha durado la anestesia, que llaman los hombres?iCiencia de Dios, Teodicea! isi se me echa a vivir en tales condiciones, anestesiado totalmente, volteada mi sensibilidad para adentro! iAh doctores de las sales, hombres de las esencias, prójimos de las bases! iPido se me deje con mi tumor de conciencia, con mi irritada lepra sensitiva, ocurra, lo que ocurra, aunque me muera! Dejadme dolerme, si lo queréis, mas dejadme despierto de sueño, con todo el universo metido, aunque fuese a las malas, en mi temperatura polvorosa.

En el mundo de la salud perfecta, se reirá por esta perspectiva en que padezco; pero, en el mismo plano y cortando la baraja del juego, percute aquí otra risa de contrapunto.

En la casa del dolor, la queja arranca frontera excesiva. no se reconoce en esta queja de dolor, a la propia queja de la dicha en éxtasis, cuando el amor y la carne se eximen de azor y cuando, al regresar, hay discordia bastante para el diálogo. 
¿Dónde está, pues, el otro flanco de esta queja de dolor, si, a estimarla en conjunto, parte ahora del lecho de un hombre?

De la casa del dolor parten quejas tan sordas e inefables y tan colmadas de tanta plenitud que llorar por ellas sería poco, y sería ya mucho sonreír.

Se atumulta la sangre en el termómetro.

iNo es grato morir, señor, si en la vida nada se deja y si en la muerte nada es posible, sino sobre lo que se deja en la vida!

iNo es grato morir, señor, si en la vida nada se deja y si en la muerte nada es posible, sino sobre lo que se deja en la vida!

iNo es grato morir, señor, si en la vida nada se deja y si en la muerte nada es posible, sino sobre lo que pudo dejarse en la vida!

\section{AS JANELAS ESTREMECERAM - Tradução de Thiago de Mello}

As janelas estremeceram, elaborando uma metafísica do universo. Vidros caíram. Um enfermo

solta a sua queixa: a metade pela boca transbordante de língua, e inteira pelo ânus de suas costas.

É o furacão. Uma castanheira dos jardins das Tulherias é derrubada pelo sopro do vento, que sopra a oitenta metros por segundo. Caíram capitéis do bairro antigo, fendendo, matando.

De que ponto, me pergunto ouvindo as duas margens dos oceanos, de que lugar vem este furacão tão digno de crédito, tão honrado de dívida, certeiro contra as janelas do hospital? Ai, as direções imutáveis que oscilam entre o furacão e essa dor de tossir ou defecar! Ai, as direções imutáveis, que semeiam a morte nas entranhas de um hospital e despertam a qualquer momento células clandestinas nos cadáveres.

O que pensaria de si o enfermo aí em frente, este que está dormindo, se houvesse percebido o furacão. O pobre dorme, de boca para cima, à cabeça de sua morfina, aos pés de toda a sua prudência. Um nadinha a mais ou a menos na sua dose e lá vai ser enterrado, o ventre roto, a boca para cima, surdo ao furacão, surdo a seu ventre roto, diante do qual os médicos costumam dialogar e cavilar demoradamente, para, finalmente, pronunciar suas triviais palavras de homens.

A família rodeia o doente, agrupando-se diante de suas têmporas regressivas, indefesas, suarentas. Já não existe lar, a não ser ali, em torno da mesa de cabeceira do parente enfermo, onde montam guarda impacientes seus sapatos vazios, suas cruzes de reserva, suas pílulas de ópio. A família rodeia a mesinha pelo espaço de um alto dividendo. Uma mulher acomoda bem, na beira da mesa, uma xícara que estava para cair. 
Quanto tempo durou a anestesia, como dizem os homens? Ciência de Deus, Teodicéia!, se me levam a viver em tais condições, totalmente anestesiado, minha sensibilidade voltada para dentro! Ah doutores dos sais, homens das essências, próximos das bases! Peço que me deixem com o meu tumor de consciência, com a minha irritada lepra sensitiva, aconteça o que acontecer, não faz mal que eu morra. Deixai que eu sofra, se quiserdes, mas me deixai desperto de sono, com o universo inteiro metido, mesmo que de má vontade, na minha temperatura polvorosa.

(...)

Não é grato morrer, meu senhor, se na vida nada se deixa e se na morte nada é possível, a não ser sobre o que se deixa na vida!

Não é grato morrer, meu senhor, se na vida nada se deixa e se na morte nada é possível, a não ser sobre o que se deixa na vida!

Recebido em: 26/11/2021

Aceite em: 08/12/2021 